\title{
Diversidade de bactérias que nodulam siratro em três sistemas de uso da terra da Amazônia Ocidental
}

\author{
Ederson da Conceição Jesus ${ }^{(1)}$, Fátima Maria de Souza Moreira ${ }^{(1)}$, Ligiane Aparecida Florentino(1), \\ Maria Isabel Dantas Rodrigues ${ }^{(1)}$ e Marcelo Silva de Oliveira ${ }^{(2)}$
}

(1)Universidade Federal de Lavras (Ufla), Dep. de Ciência do Solo, Caixa Postal 3037, CEP 37200-000 Lavras, MG. E-mail: edersonjesus@hotmail.com,fmoreira@ufla.br, ligiflorentino@yahoo.com.br, bel_florestal@yahoo.com.br(2)Ufla, Dep. de Ciências Exatas, Caixa Postal 37, CEP 37200-000 Lavras, MG. E-mail: marcelso@ufla.br

\begin{abstract}
Resumo - O objetivo deste trabalho foi verificar o efeito de três sistemas de uso da terra da Amazônia Ocidental sobre a diversidade fenotípica de bactérias que nodulam siratro. Os sistemas estudados foram cultivo de mandioca, cultivo de pupunheira e floresta de terra firme. As densidades de bactérias foram avaliadas pela técnica do número mais provável, pela inoculação de suspensões de solo diluídas em siratro (Macroptilium atropurpureum), e foram semelhantes nas áreas estudadas. Foram caracterizados 257 isolados, provenientes dos nódulos de siratro, os quais formaram 63 grupos culturais a $80 \%$ de similaridade. Poucos isolados foram obtidos a partir de solo sob floresta, enquanto um maior número de isolados foi obtido nas áreas cultivadas. A diversidade pelo índice de Shannon e a riqueza foram maiores na área com mandioca e menores na floresta. Porém, a riqueza foi similar nos três sistemas quando determinada pela análise de rarefação. Houve diferença na proporção de tipos de culturais, a qual pôde ser explicada pela diferença na utilização da terra. Houve influência dos sistemas de uso da terra sobre a diversidade de bactérias que nodulam leguminosas.
\end{abstract}

Termos para indexação: rizóbio, Macroptilium atropurpureum, densidade, caracterização cultural.

\section{Leguminosae nodulating bacteria diversity from three different land use systems in Brazilian Western Amazon}

\begin{abstract}
The aim of this work was to evaluate the effect of three different land use systems from the Brazilian Western Amazon on Leguminosae nodulating bacteria diversity. The land use systems studied were cassava crop, peach palm crop and upland forest. Rhizobial densities were evaluated by the most probable number technique, after inoculation of Macroptilium atropurpureum with diluted soil samples, and they were similar for the three systems studied. Two hundred and fifty-seven bacteria isolated from the nodules were characterized and clustered into 63 groups of isolates with $80 \%$ similarity. Few isolates were obtained from forest, whereas a large number of isolates was obtained in the crop systems. The highest richness and Shannon diversity were found in the cassava crop and the lowest ones were found in the forest. However, the richness was similar for the three systems when it was determined with a rarefaction analysis. Differences in the proportion of types of growth were found and can be explained by differences amongst the systems. The land use systems influenced the Leguminosae nodulating bacterial diversity.
\end{abstract}

Index terms: rhizobia, Macroptilium atropurpureum, density, cultural characteristics.

\section{Introdução}

A Região Amazônica possui imensa diversidade de espécies vegetais. Um hectare de floresta pode conter de 100 a 300 espécies diferentes de árvores, dependendo do local e do diâmetro mínimo de caule escolhido como limite inferior para a amostragem (CIMA, 1991). Entre as famílias botânicas presentes na Amazônia, a família Leguminosae é a mais rica em espécies e se situa entre as cinco famílias com o maior número de indivíduos (Moreira et al., 1992). Uma das particularidades desta família é que grande parte das espécies conhecidas é capaz de formar nódulos em simbiose com bactérias diazotróficas conhecidas genericamente como rizóbios.

Atualmente, a avaliação da diversidade de bactérias tem sido fortemente influenciada pelo uso de técnicas moleculares. Conforme Woese (1987), a capacidade de se realizar o seqüenciamento de ácidos nucléicos teve um grande impacto tanto na microbiologia como na 
classificação dos microrganismos. Contudo, além do seqüenciamento, existem várias outras técnicas disponíveis para a caracterização de microrganismos, as quais levam em consideração tanto características fenotípicas como genotípicas, como, por exemplo, eletroforese de proteína total, perfil de ácidos graxos, sorologia e avaliação de características culturais e morfológicas dos microrganismos (Vandamme et al., 1996).

A avaliação das características culturais e morfológicas é o primeiro passo para a identificação de novos grupos taxonômicos de microrganismos e é muito útil, em laboratórios que não têm acesso a tecnologias sofisticadas, por ser de baixo custo. Atualmente, buscase uma taxonomia polifásica e as características culturais fazem parte dos caracteres utilizados para esta classificação (Vandamme et al., 1996). Estas características podem indicar diferenças fisiológicas importantes entre microrganismos, que podem ser detectadas posteriormente mediante estudos mais refinados (Pelczar et al., 1981). Um exemplo é o gênero Mesorhizobium, no qual foram incluídos isolados que apresentavam algumas características fenotípicas diferenciadas do gênero Rhizobium, inclusive algumas estirpes apresentando taxa de crescimento intermediária, sugerindo a existência de diferenças metabólicas importantes (Moreira et al., 1993; Jarvis et al., 1997; De Lajudie et al., 1998).

Características culturais relevantes que podem ser avaliadas são o tempo de formação de colônias isoladas e a alteração do $\mathrm{pH}$ do meio de cultura com azul de bromotimol como indicador de diferenças fisiológicas entre gêneros (Jordan, 1984; Moreira \& Pereira, 2001). Além destas, outras características utilizadas são produção de exopolissacarídeos, tamanho, formato, cor, e tempo de formação de colônias e alteração do $\mathrm{pH}$ do meio de cultura (Vincent, 1970; Moreira et al., 1993; Odee et al., 1997). Estas características foram utilizadas com sucesso no estudo da ecologia de rizóbios (Martins et al., 1997; Moreira et al., 1993; Pereira, 2000;
Melloni, 2001), permitindo acessar a diversidade e o efeito de diferentes usos da terra sobre as comunidades destes microrganismos.

O objetivo deste trabalho foi verificar o efeito de três sistemas de uso da terra da Amazônia Ocidental sobre a diversidade fenotípica cultural de bactérias que nodulam siratro.

\section{Material e Métodos}

\section{Caracterização da área de estudo e amostragem}

O local estudado situa-se a aproximadamente $1.100 \mathrm{~km}$ a oeste de Manaus, no Município de Benjamin Constant, e está localizado na base do Rio Solimões. O clima é Afi, tropical úmido sem estação seca, de acordo com a classificação de Köppen, com pluviosidade média anual de aproximadamente $3.000 \mathrm{~mm}$ e temperatura média de aproximadamente $26^{\circ} \mathrm{C}$. A vegetação natural é do tipo floresta tropical úmida. Os sistemas avaliados estão localizados na comunidade indígena Guanabara III. A comunidade, existente há 22 anos, é formada por representantes dos índios Ticuna e é reserva da Fundação Nacional do Índio (Funai) desde o segundo semestre de 2003. Esta comunidade foi escolhida por ser uma das maiores da região e, por isso, com uma utilização mais intensa das terras para o cultivo.

Em abril de 2003 foram coletadas quatro amostras compostas de solo em três áreas de terra firme sob diferentes sistemas de uso da terra: floresta de terra firme, cultivo de mandioca (Manihot esculenta L.) e cultivo de pupunheira (Bactris gasipaes Kunth). Estas foram escolhidas de modo a constituírem um gradiente de intensidade de utilização da terra (Tabela 1). Ao contrário da mandioca, a pupunheira é uma cultura que permanece por mais tempo na área de cultivo e, portanto, a utilização da terra é menos intensa nas áreas com pupunheira. Na comunidade, a pupunheira é utilizada para a produção de frutos e o cultivo tinha cinco anos no momento da coleta das amostras. O cultivo de mandioca fica localizado em uma área mais intensamente

Tabela 1. Altitude, coordenadas geográficas, características químicas e textura dos solos de três áreas sob diferentes sistemas de uso da terra da Amazônia Ocidental.

\begin{tabular}{|c|c|c|c|c|c|c|c|c|c|c|c|}
\hline Sistemas de uso & Altitude (m) & Coordenadas geográficas & $\mathrm{pH}$ & $\mathrm{Ca}^{2+}$ & $\begin{array}{c}\mathrm{Mg}^{2+} \\
\left.\mathrm{mol}_{\mathrm{c}} \mathrm{dm}^{-3}\right)\end{array}$ & $\mathrm{Al}^{3+}$ & P & $\begin{array}{c}\mathrm{K} \\
(\mathrm{mg} \mathrm{dm}\end{array}$ & $\begin{array}{c}S \\
-\end{array}$ & $\begin{array}{l}\text { Matéria orgânica } \\
\left(\operatorname{dag~dm}^{-3}\right)\end{array}$ & Textura \\
\hline Floresta & 84 & $4^{\circ} 25^{\prime} 20,8^{\prime \prime S} 69^{\circ} 54^{\prime} 49,7^{\prime \prime} \mathrm{W}$ & 4,6 & 2,7 & 1,5 & 3,9 & 4,5 & 52,5 & 3,6 & 2,7 & Média \\
\hline Cultivo de mandioca & 93 & $4^{\circ} 24^{\prime} 44,9^{\prime \prime} \mathrm{S} 69^{\circ} 54^{\prime} 42,3^{\prime \prime} \mathrm{W}$ & 4,6 & 4,8 & 1,8 & 6,4 & 5,4 & 51,3 & 4,1 & 3,1 & Argilosa \\
\hline Cultivo de pupunheira & 85 & $4^{\circ} 25^{\prime} 3,9^{\prime \prime S} 69^{\circ} 54^{\prime} 42,1^{\prime \prime} \mathrm{W}$ & 4,8 & 4,7 & 1,5 & 6,8 & 4,5 & 57,0 & 5,4 & 2,9 & Argilosa \\
\hline
\end{tabular}


utilizada para agricultura, enquanto o cultivo de pupunheira se localiza em uma área menos impactada. O manejo das áreas cultivadas é realizado manualmente.

Cada amostra composta constituiu-se de 20 subamostras, coletadas aleatoriamente dentro de um quadrado de $5 \times 5 \mathrm{~m}$, à profundidade de $0-20 \mathrm{~cm}$. Na área cultivada com a pupunheira foram coletadas três amostras simples. As amostras destinadas para análise microbiológica foram acondicionadas em sacos de plástico Millipore esterilizados e enviadas para o laboratório de Microbiologia do Solo da Universidade Federal de Lavras, onde foram conservadas a $4^{\circ} \mathrm{C}$. Parte das amostras foi enviada para análises química e física no Laboratório de Fertilidade da Universidade Federal de Lavras (Tabela 1).

Isolamento, caracterização e determinação da densidade populacional de bactérias que nodulam siratro

Sessenta gramas de cada amostra composta de solo foram diluídos em $60 \mathrm{~mL}$ de solução salina $\mathrm{NaCl}$ 0,85\%. Os frascos contendo as amostras de solo foram agitados por 30 minutos, a 50 rpm. Posteriormente, cada uma destas suspensões foi submetida a uma série de diluições de $10^{-1}$ a $10^{-6}$ e alíquotas de $1 \mathrm{~mL}$ de cada diluição foram inoculadas em plantas de siratro (Macroptilium atropurpureum), cultivadas em sacos de plástico Millipore, contendo $250 \mathrm{~mL}$ de solução nutritiva de Jensen, sem nitrogênio (Jensen, 1942 citado por Vincent, 1970), com três repetições para cada passo de diluição. Foram adicionadas testemunhas sem inoculação para verificar possíveis contaminações do experimento. As estimativas do número mais provável (NMP) foram realizadas pelo programa MPNES (Bennett et al., 1990). O aparecimento de nódulos nas raízes foi avaliado periodicamente e as plantas foram coletadas 60 dias após a montagem do experimento e inoculação.

Todos os nódulos formados no siratro foram utilizados no isolamento das bactérias. Os nódulos foram desinfestados superficialmente conforme Vincent (1970) e as bactérias foram isoladas em placas contendo meio de cultura 79, também conhecido como YMA (Vincent, 1970), com azul de bromotimol e com pH 6,8 (Fred \& Waksman, 1928). As bactérias foram cultivadas sob temperatura de $28^{\circ} \mathrm{C}$. Colônias isoladas foram selecionadas e plaqueadas para purificação. Após a purificação dos isolados, as seguintes características culturais foram avaliadas: alteração do pH do meio de cultura, taxa de crescimento avaliada pelo tempo de formação de colônias isoladas, características das colônias (tamanho, formato, borda, elevação, superfície, transmissão de luz e coloração das colônias) e produção de goma (polissacarídeos extracelulares).

A caracterização foi realizada sete dias após a repicagem das bactérias. Quando as colônias apareceram após este período, a caracterização foi realizada após 12 dias de crescimento. O método utilizado foi o de Moreira (1991), com modificações, a fim de tornar mais discriminativas as alterações de $\mathrm{pH}$ e a produção de goma. A avaliação do $\mathrm{pH}$ foi realizada mediante a comparação da coloração do meio de cultura, após o crescimento da bactéria em placas com meio 79 e pH ajustado nos valores 5,0, 6,0, 6,3, 6,5, 6,7, 6,8, 7,0, 7,2, $7,5,8,0$, e 9,0 . Foram consideradas as seguintes faixas de dias de aparecimento de colônia: 1 dia, crescimento muito rápido; 2-3 dias, crescimento rápido; 4-5 dias, crescimento intermediário; 6-10 dias, crescimento lento; mais de 10 dias, crescimento muito lento. A produção de goma foi dividida em seis faixas: goma abundante, muita goma, produção intermediária, pouca goma, seca e muito seca. A coloração das colônias foi avaliada com o auxílio da carta de Munsell e expressa na forma de matiz, valor e croma indicados. Tamanho, formato, borda, elevação, superfície, transmissão de luz e coloração das colônias foram avaliados de acordo com Eklund \& Charles (1967).

Os isolados foram agrupados com base na caracterização cultural, juntamente com estirpes tipo ou referência de espécies já descritas de rizóbio: CIAT899 ${ }^{\mathrm{T}}$, Rhizobium tropici; LMG $6214^{\mathrm{T}}$, Rhizobium galegae bv. orientalis; USDA205' , Sinorhizobium fredii cv. fredii; USDA1037', Sinorhizobium medicae; ATCC33669T ${ }^{\mathrm{T}}$, Mesorhizobium loti; BR29, Bradyrhizobium elkanii; e ATCC10324" Bradyrhizobium japonicum. Foram utilizadas 11 características para o agrupamento. Os dendrogramas foram construídos pelo método UPGMA (método da média aritmética não ponderada), com a utilização do coeficiente de Jaccard, com o programa estatístico NTSYS (Numerical Taxonomic and Multivariate Analysis System, version 2.0, Applied Biostatistics, New York). Cento e vinte e três representantes dos grupos formados foram autenticados em siratro.

\section{Análise dos dados}

A probabilidade de ocorrência dos resultados da série de diluição encontrados no teste do número mais pro- 
vável (NMP) foi determinada pela avaliação da faixa de transição (Woomer, 1994). Os grupos culturais formados a $80 \%$ de similaridade foram utilizados no cálculo do índice de diversidade de Shannon e na análise de rarefação. Os valores obtidos em relação ao índice de Shannon foram submetidos ao teste t de Student (Magurran, 1987). Foram construídas curvas com a variação do índice de Shannon em função do número de isolados e curvas de acumulação de grupos culturais com o auxílio do programa Estimates, versão 5.0 (Colwell, 1997). O programa selecionou os isolados ao acaso de modo a constituir amostras com um, até o número total de isolados. Os dados foram aleatorizados cem vezes. Na comparação entre as áreas na seleção de grupos de bactérias de crescimento diferente, foi utilizado o teste de qui-quadrado. A análise de rarefação foi realizada conforme Magurran (1987).

\section{Resultados e Discussão}

As densidades de células de bactérias que nodulam siratro variaram de 63 células $\mathrm{g}^{-1}$ solo na floresta a

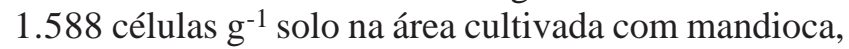
contudo não houve diferença estatística significativa no número de células presentes na maioria das amostras. Cinco dos resultados das séries de diluição encontrados apresentaram probabilidade de ocorrência menor que 0,001, a qual é o limite recomendado por Woomer (1994) para a seleção de resultados (Tabela 2). As densidades encontradas em Benjamin Constant são próximas às densidades encontradas por Pereira (2000) em solos de floresta (210 células $\mathrm{g}^{-1}$ ) e cultivo de mandioca (2.112 células g ${ }^{-1}$ ), no Município de Theobroma, RO.

A maior densidade de bactérias que nodulam siratro nos solos cultivados pode ocorrer em razão do estímulo por parte das plantas cultivadas. Há trabalhos que mostram que espécies cultivadas podem ter efeito estimu-

Tabela 2. Número mais provável (NMP) de células de rizóbio em três sistemas de uso da terra da Amazônia Oriental.

\begin{tabular}{lccc}
\hline Sistemas de uso & Amostra & NMP & Intervalo de confiança (95\%) \\
\hline Floresta & I & 63 & $21-188$ \\
& II & 86 & $29-255$ \\
& III & $57^{(1)}$ & $19-169$ \\
& IV & $69^{(1)}$ & $23-207$ \\
\hline Cultivo de mandioca & I & 85 & $28-252$ \\
& II & $78^{(1)}$ & $26-233$ \\
& III & $238^{(1)}$ & $80-709$ \\
\hline Cultivo de pupunheira & IV & 1.588 & $534-4.726$ \\
& I & 1.236 & $415-3.678$ \\
& II & 274 & $92-816$ \\
& III & $247^{(1)}$ & $83-735$ \\
& IV & 422 & $142-1.256$ \\
\hline
\end{tabular}

(1)Padrões com probabilidade de ocorrência menor que 0,001. lante sobre populações de rizóbios, mesmo que não sejam hospedeiras. Venkateswarlu et al. (1997) verificaram que houve estímulo de populações de rizóbios em solos cultivados com sorgo, enquanto mamona e girassol desestimularam as populações. Pereira (2000) encontrou maiores populações de rizóbios em solos da Amazônia utilizados para pastagem, até mesmo maiores que em área cultivada com feijoeiro. A autora atribuiu este resultado a melhores condições químicas (e.g. maiores valores de $\mathrm{pH}$, maior saturação de bases e menores teores de alumínio) encontradas no solo pastagem.

Foram obtidos 257 isolados em cultura pura com características típicas de rizóbios. A maior parte destes isolados foi proveniente das áreas cultivadas. Foram obtidos poucos isolados da floresta em razão da baixa nodulação de siratro com inoculação de suspensões provenientes de solos desta área. Os isolados encontrados apresentaram crescimento variando de muito rápido a muito lento e foram encontrados isolados que acidificaram, alcalinizaram e que não alteraram o pH do meio de cultura, os quais foram divididos em cinco tipos culturais, de acordo com a taxa de crescimento e alteração do pH do meio de cultura (Figura 1).

Os isolados que acidificaram o meio de cultura (IAM) apresentaram crescimento rápido e muito rápido. A maioria deles apresentou características culturais dos gêneros Rhizobium, Sinorhizobium e Mesorhizobium, conforme Moreira \& Pereira (2001). A maioria dos isola-

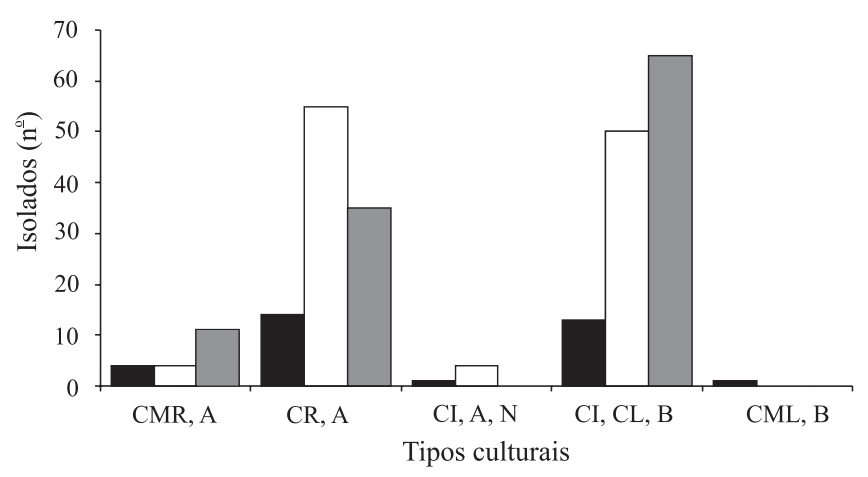

Figura 1. Distribuição dos isolados de bactérias que nodulam siratro em 5 tipos culturais baseados no tempo para a formação de colônias isoladas e na alteração do pH do meio de cultura para floresta ( $\square$ ) e áreas cultivadas com mandioca ( $\square$ ) e pupunheira ( $\square$ ). CMR, crescimento muito rápido; $\mathrm{CR}$, crescimento rápido; CI, crescimento intermediário; CL, crescimento lento; CML, crescimento muito lento; A, acidificam o meio de cultura; $\mathrm{B}$, alcalinizam o meio de cultura. 
dos que alcalinizaram o meio de cultura (IALM) apresentou características culturais do gênero Bradyrhizobium, conforme Jordan (1984) e Moreira \& Pereira (2001).

A maior parte dos isolados provenientes da área cultivada com pupunheira apresentou crescimento lento e alcalinização do meio de cultura (Figura 1). Na floresta e na área cultivada com mandioca, foi observado um número maior de isolados de crescimento rápido e muito rápido, com acidificação do meio de cultura (Figura 1). Para avaliar se este padrão foi dependente da forma de utilização da terra, os dados foram submetidos ao teste de qui-quadrado, cujo resultado foi 22,07 e o esperado, a 1\% de probabilidade, 20,09. Este resultado mostra que a distribuição diferenciada dos isolados nos tipos culturais pode ser explicada pela forma diferente de utilização da terra. A maior proporção de IAM na floresta em relação aos IALM corrobora observações anteriores, em floresta localizada em Theobroma, RO (Pereira, 2000). A princípio, o resultado encontrado em

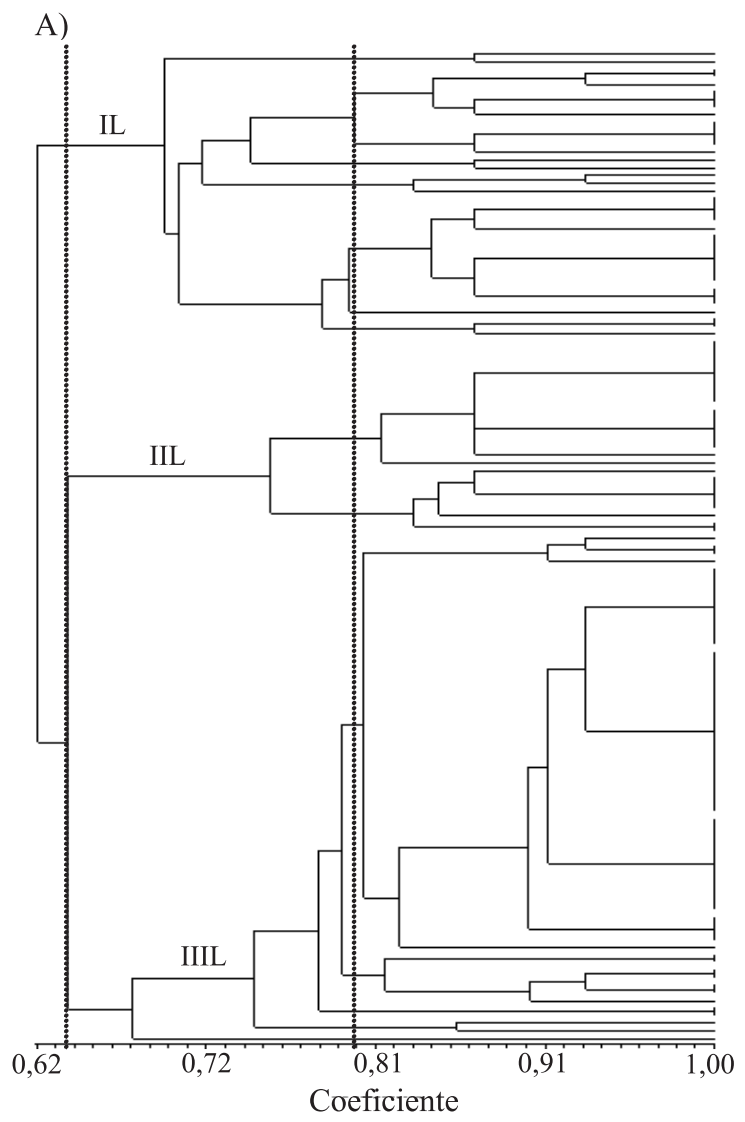

relação à floresta é inesperado, visto que um grande número de isolados obtidos a partir de leguminosas florestais do Brasil apresentam crescimento lento e alcalinização do meio de cultura, características do gênero Bradyrhizobium (Moreira et al., 1993). Outro fator pelo qual se esperaria encontrar mais isolados de crescimento lento na floresta é a utilização de siratro como planta-isca. O siratro é considerado uma espécie nodulada, principalmente, por estirpes do gênero Bradyrhizobium (Gibson et al., 1982; Thies et al., 1991; Odee et al., 1997). Porém, neste e em outros estudos (Pereira, 2000), não se verificou seletividade do siratro para estirpes de crescimento lento uma vez que uma proporção significativa de estirpes de crescimento rápido nodularam esta espécie.

Pelo agrupamento dos IALM, observa-se que se formaram três grupos a $64 \%$ de similaridade (IL, IIL e IIIL) (Figura 2A). O grupo IL foi constituído praticamente por isolados oriundos da área cultivada com

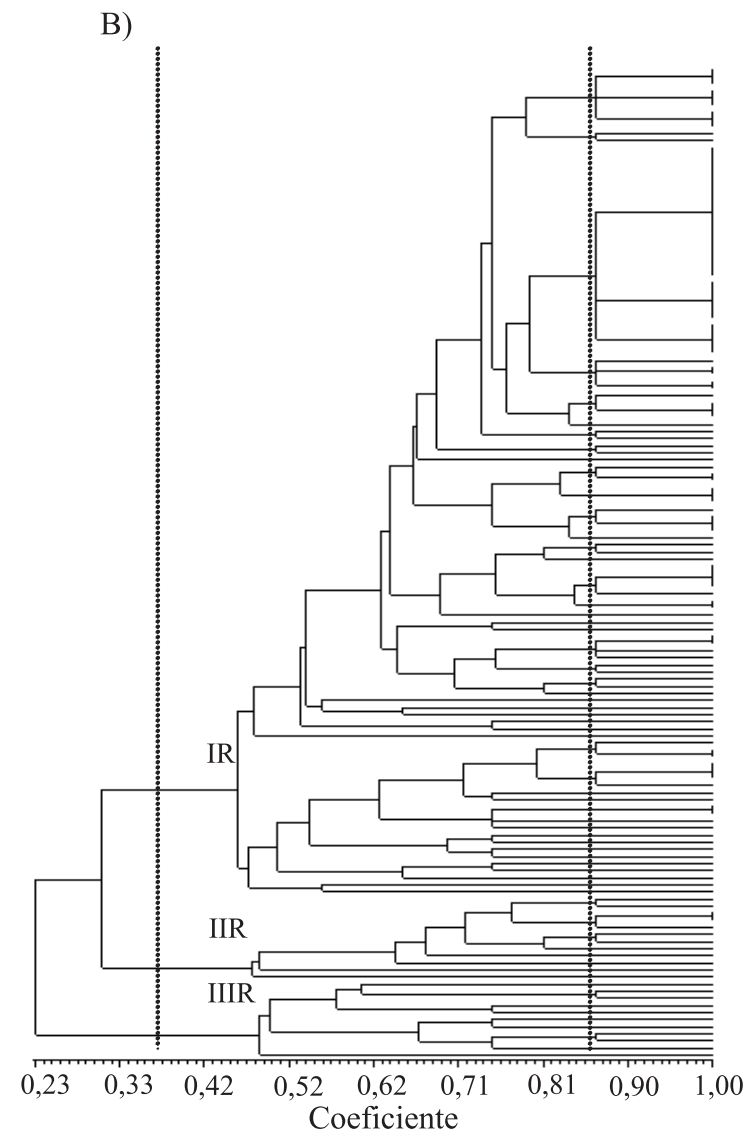

Figura 2. Dendrogramas de similaridade baseados em características fenotípicas culturais para isolados de bactérias que nodulam siratro, que alcalinizam (A) e que acidificam (B) o meio de cultura. As linhas verticais indicam o nível de similaridade entre os principais grupos formados e os grupos formados a 80\% de similaridade. Grupos: IL, IIL e IIIL, 64\%; IR, IIR e IIIR, 31\%. 
pupunheira. A maior parte dos isolados do grupo IIL foi oriunda da área cultivada com mandioca e se agruparam juntamente com a estirpe ATCC10324 ${ }^{\mathrm{T}}$, tipo de Bradyrhizobium japonicum. Também neste grupo está a maioria dos IALM da floresta. A estirpe BR29, estirpe referência de Bradyrhizobium elkanii, é utilizada como inoculante da soja no Brasil desde 1979 (Freire \& Vernetti, 1999), e está no grupo IIIL. Este grupo é constituído, em sua maior parte, por isolados oriundos das áreas cultivadas. $\mathrm{O}$ agrupamento de grande parte dos IALM, das áreas cultivadas, indica que o cultivo selecionou IALM culturalmente semelhantes entre si, tanto na área cultivada com mandioca como na cultivada com pupunheira. O efeito da utilização da terra sobre a seleção de grupos diferentes de rizóbios foi observado por Pereira (2000), e áreas com diferentes tipos de manejo foram diferenciadas pelo agrupamento de rizóbios com base em parâmetros morfológicos.

Pelo agrupamento dos IAM, pode-se distinguir três grandes grupos a $31 \%$ de similaridade (IR, IIR e IIIR) (Figura 2B). No grupo IR, estão quase todas as estirpes referência de Rhizobium e Sinorhizobium, com exceção da estirpe referência de Sinorhizobium meliloti (BR7411), que está no grupo IIIR. A maioria dos isolados se agrupou no grupo IR. Porém, os isolados das áreas cultivadas não apresentaram um padrão de distribuição claro entre os grupos e subgrupos formados, como ocorreu em relação aos isolados de crescimento lento.

Num nível maior de discriminação, a 80\% de similaridade, formaram-se 63 grupos, sendo 50 grupos de IAM e 13 grupos de IALM, evidenciando maior diversidade entre os IAM. As áreas cultivadas com mandioca e pupunheira e a floresta apresentaram 39, 32 e 17 grupos, respectivamente (Tabela 3). Como houve uma grande diferença no número de isolados obtidos nas áreas cultivadas e na floresta, foi realizada uma análise de rarefação (Magurran, 1987). De acordo com esta análise, se nas áreas cultivadas fosse coletado o mesmo número de isolados que foram obtidos na floresta, esti-

Tabela 3. Riqueza e diversidade em grupos fenotípicos culturais de rizóbio isolados de três sistemas de uso da terra da Amazônia Ocidental, e estimativa de grupos culturais pela análise de rarefação.

\begin{tabular}{lccc}
\hline Variáveis & Floresta & Mandioca & Pupunheira \\
\hline Indivíduos & 33 & 113 & 111 \\
Riqueza de grupos culturais $_{\text {Shannon }^{(1)}}$ & 17 & 39 & 32 \\
Rarefação & $2,64 \mathrm{~b}$ & $3,11 \mathrm{a}$ & $2,73 \mathrm{~b}$ \\
\hline
\end{tabular}

(1)Valores com letras iguais não diferem entre si pelo teste t Student, a 5\% de probabilidade ma-se que 17 grupos seriam encontrados na área cultivada com mandioca e 15 grupos seriam encontrados na área cultivada com pupunheira (Tabela 3).

A diversidade calculada pelo índice de Shannon foi maior na área cultivada com mandioca e menor nas áreas de floresta e cultivo de pupunheira, as quais não diferiram estatisticamente entre si (Tabela 3 ). As curvas de variação para o índice de Shannon tenderam a atingir a assíntota (Figura 3). Isto significa que a coleta de mais isolados levaria a uma variação pequena no valor do índice de Shannon, revelando que foi realizada uma boa estimativa da diversidade de rizóbios que nodulam siratro com base neste índice. Este índice é razoavelmente independente do tamanho da amostra, de modo que um pequeno número de amostras é necessário para se obter um índice seguro para efeitos de comparação (Odum, 1988). Abordagem semelhante foi utilizada por Coutinho et al. (1999) no estudo de comunidades de rizóbios em solos cultivados.

A determinação do ponto de estabilização da curva é, de certo modo, subjetiva (Magurran, 1987). Contudo, observa-se que a variação do valor do índice de Shannon em relação às comunidades das áreas cultivadas tornase pequena a partir de 60 isolados, de modo que este pode ser considerado um número razoável de isolados para a boa determinação da diversidade em cada uma das áreas estudadas. A curva para a comunidade da floresta acompanha a curva da comunidade da área cultivada com mandioca, indicando que a diversidade na floresta pode ser semelhante à diversidade naquela

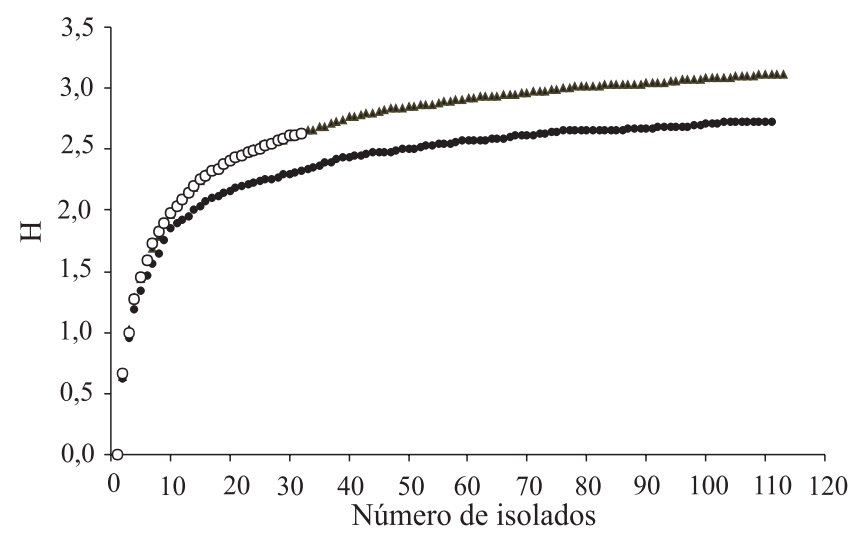

Figura 3. Variação do índice de Shannon (H) em função do número de isolados de bactérias que nodulam leguminosas, coletados em áreas com cultivo de mandioca, em áreas com um cultivo de mandioca $(\boldsymbol{\Delta})$, cultivo de pupunheira $(\boldsymbol{O})$ e floresta ( $\bigcirc$ ), na Amazônia Ocidental. 
comunidade. Como o número de isolados obtidos a partir da floresta foi muito pequeno, é possível que a diversidade neste sistema tenha sido subestimada. Além disso, a análise de rarefação indica que o número de grupos culturais da área cultivada com mandioca e da floresta seriam semelhantes se o mesmo número de isolados fosse coletado nas duas áreas.

\section{Conclusões}

1. Os sistemas de uso da terra alteram a composição das comunidades de bactérias que nodulam siratro.

2. A área de cultivo de mandioca apresenta maior riqueza e diversidade de bactérias que nodulam siratro.

\section{Agradecimentos}

Ao GEF/UNEP, pelo financiamento do projeto GF/ 275-02/4517; à Capes, pela concessão de bolsa de mestrado a Ederson da C. Jesus; ao CNPq, pela bolsa de produtividade concedida à Fátima M. S. Moreira, e de iniciação científica, a Maria Isabel D. Rodrigues e Ligiane A. Florentino.

\section{Referências}

BENNETT, J.E.; WOOMER, P.L.; YOST, R.S. User manual for MPNES most-probable-number enumeration system ver. 1.0. NifTAL project and University of Hawaii, 1990.

COLWELL, R.K. Estimates: statistical estimation of species richness and shared species from samples. Version 5. User's Guide and application published at 1997. Disponível em: <http:// viceroy.eeb.uconn.edu/estimates>. Acesso em: 2004.

COMISSÃO INTERMINISTERIAL PARA PREPARAÇÃO DA CONFERÊNCIA DAS NAÇÕES UNIDAS SOBRE MEIO AMBIENTE E DESENVOLVIMENTO - CIMA. O desafio do desenvolvimento sustentável: relatório do Brasil para a conferência das Nações Unidas sobre meio ambiente e desenvolvimento. Brasília: Cima, 1991. 204p.

COUTINHO, H.L.C.; OLIVEIRA, V.M.; LOVATO, A.; MAIA, A.H.N.; MANFIO, G.P. Evaluation of the diversity of rhizobia in Brazilian agricultural soils cultivated with soybeans. Applied Soil Ecology, v.13, p.159-167, 1999.

DE LAJUDIE, P.; WILLEMS, A.; NICK, G.; MOREIRA, F.; MOLOUBA, F.; HOSTE, B.; TORCK, U.; NEYRA, M.; COLLINS, M.D.; LINDSTRÖM, K.; DREYFUS, B.; GILLIS, M. Characterization of tropical tree rhizobia and description of Mesorhizobium plurifarium sp. nov. International Journal of Systematic Bacteriology, v.48, p.369-382, 1998.
EKLUND, G.; LANKFORD, C.E. Laboratory manual for general microbiology. New Jersey: Prentice-Hall, 1967.

FRED, E.B.; WAKSMAN, S.A. Laboratory manual of general microbiology - with special reference to the microorganisms of the soil. New York: McGraw-Hill Book Company, 1928. 145p.

FREIRE, J.R.J.; VERNETTI, F.J. A pesquisa com soja, a seleção de rizóbio e a produção de inoculantes no Brasil. Pesquisa Agropecuária Gaúcha, v.5, p.117-126, 1999.

GIBSON, A.H.; DREYFUS, B.L.; DOMMERGUES, Y.R. Nitrogen fixation by legumes in the tropics. Hague, Holanda: Martinez Nijhoff/Dr. W. Junk Publishers, 1982.

JARVIS, B.D.W.; VAN BERKUM, P.; CHEN, W.X.; NOUR, S.M.; FERNANDEZ, M.P.; CLEYET-MAREL, J.C.; GILLIS, M. Transfer of Rhizobium loti, Rhizobium huakuii, Rhizobium cicer, Rhizobium mediterraneum and Rhizobium tianshansense to Mesorhizobium gen. nov. International Journal of Systematic Bacteriology, v.47, p.895-898, 1997.

JENSEN, H.L. Nitrogen fixation in leguminous plants. I. General characters of root-nodule bacteria isolated from species of Medicago and Trifolium in Australia. Proceedings of the Linnean Society of New South Wales, v.66, p.98-108, 1942.

JORDAN, D.C. Rhizobiaceae. In: HRIEG, N.R.; HOLT, J.G. (Ed.). Bergey's manual of systematic bacteriology. 1984. v.1, p.235256.

MAGURRAN, A.E. Ecological diversity and its measurement. New Jersey: Princeton, 1987. 179p.

MARTINS, L.M.V.; NEVES, M.C.P.; RUMJANEK, N.G. Growth characteristics and symbiotic efficiency of rhizobia isolated from cowpea nodules of the north-east region of Brazil. Soil Biology and Biochemistry, v.29, p.1005-1010, 1997.

MELLONI, R. Densidade e diversidade de bactérias diazotróficas e fungos micorrízicos arbusculares em solos de mineração de bauxita. 2001. 173p. Tese (Doutorado) - Universidade Federal de Lavras, Lavras.

MOREIRA, F.M.S. Caracterização de estirpes de rizóbio isoladas de espécies florestais pertencentes a diversos grupos de divergência de Leguminosae introduzidas ou nativas da Amazônia e Mata Atlântica. 1991. 158p. Tese (Doutorado) Universidade Federal Rural do Rio de Janeiro, Itaguaí.

MOREIRA, F.M.S.; GILLIS, M.; POT, B.; KERSKERS, K.; FRANCO, A.A. Characterization of rhizobia isolated from different divergence groups of tropical leguminosae by comparative polyacrylamide gel eletrophoresis of their total proteins. Systematic and Applied Microbiology, v.17, p.135-146, 1993.

MOREIRA, F.M.S.; PEREIRA, E.G. Microsymbionts: Rhizobia. In: SWIFT, M.; BIGNELL, D. (Ed.). Standard methods for assessment of soil biodiversity and land use practice. Bogor, Indonesia, 2001. 34p. 
MOREIRA, F.M.S.; SILVA, M.F. da; FARIA, S.M. de. Occurrence of nodulation in legume species in the Amazon region of Brazil. New Phytologist, v.121, p.563-570, 1992.

ODEE, D.W.; SUTHERLAND, J.M.; MAKATIANI, E.T.; MCINROY, S.G.; SPRENT, J.I. Phenotipic characteristics and composition of rhizobia associated with woody legumes growing in diverse Kenyan conditions. Plant and Soil, v.188, p.65-75, 1997.

ODUM, E.P. Fundamentos de ecologia. 4.ed. Lisboa: Fundação Calouste Gulbenkian, 1988. 927p.

PELCZAR, M.S.; REID, R.D.; CHAN, E.C.S. Microbiologia. São Paulo; McGraw-Hill do Brasil, v.1, 1981.

PEREIRA, E.G. Diversidade de rizóbios isolados de diferentes sistemas de uso da terra na Amazônia. 2000. 93p.Tese (Doutorado) - Universidade Federal de Lavras, Lavras.

THIES, J.E.; BOHLOOL, B.B.; SINGLETON, P.W. Subgroups of the cowpea mescellany: symbiotic specificity within Bradyrhizobium spp. for Vigna unguiculata, Phaseolus lunatus, Arachis hypogea and
Macroptilium atropurpureum. Applied and Environmental Microbiology, v.57, p.1540-1545, 1991.

VANDAMME, P.; POT, B.; GILLIS, M.; DE VOS, P.; KERSTERS, K.; SWINGS, J. Polyphasic taxonomy, a consensus approach to bacterial systematics. Microbiological Reviews, v.60, p.407-438, 1996.

VENKATESWARLU, B.; HARI, K.; KATYAL, J.C. Influence of soil and crop factors on the native rhizobial populations in soils under dryland farming. Applied Soil Ecology, v.7, p.1-10, 1997.

VINCENT, J.M. A manual for the practical study of root-nodule bacteria. Oxford: Blackwell Scientific Publications, 1970. (International Biological Programme Handbook, 15)

WOESE, C.R. Bacterial evolution. Microbiological Reviews, v.51, p.221-271, 1987.

WOOMER, P.L. Most Probable Number Counts. In:WEAVER, R.W.; ANGLE, S.; BOTTOMLEY, P.; BEZDICEK, D.; SMITH, S.; TABATABAI, A.; WOLLUM, A. (Ed.). Methods of soil analysis. Part 2. Microbiological and biochemical properties. Madison: Soil Science Society of America, 1994. p.59-79. (SSSA Book Series, 5).

Recebido em 20 de agosto de 2004 e aprovado em 22 de fevereiro de 2005 